\title{
muralpesquisa
}

\section{Mobilidade mundial de estudantes}

\author{
SÉRIES HISTÓRICAS SOBRE MOBILIDADE INTERNACIONAL DE ACADÊMICOS SINALIZAM \\ PRONUNCIADA CURVA DE CRESCIMENTO, PARTICULARMENTE DOS ANOS 1990 EM DIANTE \\ Por Manolita Correia Lima
}
Em 1975, eram 600.000; em 1985, eram 900.000; em 1995, eram 1.300.000; e, em 2006, eram 2.754.373 estudantes (UNESCO, 2008) fora de seus países de origem. A maioria concentra-se em duas macrorregiões: América do Norte e Europa Ocidental. A hegemonia exercida pelas instituições situadas nas referi- das regiões está estampada nos números: em 2006, dos 2.754.373 estudantes em circula- ção, 1.798.299 estavam em séjour de estudo

em instituições norte-americanas e européias (UNESCO, 2008). Juntas, elas representam o principal destino dos acadêmicos provenientes de todos os continentes (Tabela 1).

Curiosamente, a emissão de estudantes é geograficamente mais dispersa do que a recepção. Ao somar a população formada por acadêmicos internacionais, verifica-se que oito países são responsáveis por, aproximadamente, um terço da matrícula internacional: 920.375 de

Tabela 1- Principais países receptores de estudantes (2001-2006)

\begin{tabular}{|l|l|l|l|l|l|r|}
\multicolumn{1}{|c|}{ Países } & 2001 & 2002 & 2003 & 2004 & 2005 & 2006 \\
\hline Estados Unidos & 475.169 & 582.996 & 582.996 & 572.509 & 590.128 & 584.814 \\
\hline Reino Unido & 225.722 & 225.722 & 227.273 & 300.056 & 318.399 & 330.078 \\
\hline Alemanha & 199.132 & 219.039 & 240.619 & 260.314 & 259.797 & 259.797 \\
\hline França & 147.402 & 147.402 & 221.567 & 237.587 & 236.518 & 247.510 \\
\hline Austrália & 105.764 & 120.987 & 179.619 & 166.954 & 207.264 & 207.264 \\
\hline Canadán & 40.033 & 40.033 & 40.033 & 40.033 & 132.982 & 75.546 \\
\hline Japão & 63.637 & 74.892 & 74.892 & 117.903 & 125.917 & 130.124 \\
\hline
\end{tabular}

Fonte: recueil de données mondiales sur l'éducation. Institut de Statistique/UNESCO, 2003, 2004, 2005, 2006. 2008. 
Tabela 2 - Maiores exportadores de estudantes internacionais (2004-2006)

\begin{tabular}{|c|c|c|c|}
\hline Principais destinos & 2004 & 2005 & 2006 \\
\hline $\begin{array}{r}\text { EUA } \\
\text { Japão } \\
\text { Reino Unido }\end{array}$ & 343.126 & $\begin{array}{r}394.669 \\
92.370 \\
83.264 \\
52.677\end{array}$ & $\begin{array}{r}417.351 \\
93.672 \\
68.378 \\
50.753\end{array}$ \\
\hline $\begin{array}{r}\text { EUA } \\
\text { Austrália } \\
\text { Reino Unido }\end{array}$ & 123.559 & $\begin{array}{r}139.356 \\
84.044 \\
22.039 \\
16.685\end{array}$ & $\begin{array}{r}139.459 \\
79.219 \\
22.039 \\
19.204\end{array}$ \\
\hline $\begin{array}{r}\text { EUA } \\
\text { Japão } \\
\text { Alemanha }\end{array}$ & 95.885 & $\begin{array}{r}97.395 \\
55.731 \\
22.751 \\
5.282\end{array}$ & $\begin{array}{r}101.913 \\
61.117 \\
22.344 \\
\text { Austrália }-4.889\end{array}$ \\
\hline $\begin{array}{r}\text { EUA } \\
\text { Reino Unido } \\
\text { Austrália }\end{array}$ & 60.624 & $\begin{array}{r}65.229 \\
44.092 \\
16.179 \\
3.976\end{array}$ & $\begin{array}{r}60.225 \\
40.086 \\
6.200 \\
3.976\end{array}$ \\
\hline $\begin{array}{r}\text { Reino Unido } \\
\text { EUA } \\
\text { Suíça }\end{array}$ & 56.410 & $\begin{array}{r}63.280 \\
12.553 \\
9.024 \\
7.864\end{array}$ & $\begin{array}{r}70.696 \\
13.267 \\
\text { Áustria - } 10.174 \\
\text { EUA - } 9.142\end{array}$ \\
\hline $\begin{array}{r}\text { Reino Unido } \\
\text { Bélgica } \\
\text { EUA }\end{array}$ & 53.350 & $\begin{array}{r}52.156 \\
11.685 \\
7.583 \\
6.847\end{array}$ & $\begin{array}{r}54.046 \\
12.456 \\
9.171 \\
6.876\end{array}$ \\
\hline $\begin{array}{r}\text { Alemanha } \\
\text { EUA } \\
\text { França }\end{array}$ & 52.048 & $\begin{array}{r}50.416 \\
25.421 \\
13.029 \\
2.283\end{array}$ & $\begin{array}{r}34.816 \\
\text { EUA }-12.035 \\
\text { Alemanha }-7.107 \\
\text { Azerbaijão }-3.050\end{array}$ \\
\hline $\begin{array}{r}\text { França } \\
\text { Alemanha } \\
\text { Espanha }\end{array}$ & 51.503 & $\begin{array}{r}50.637 \\
29.859 \\
8.227 \\
4.547\end{array}$ & $\begin{array}{r}41.879 \\
29.299 \\
4.784 \\
1.613\end{array}$ \\
\hline Total grupo & 736.525 & 868.108 & 920.375 \\
\hline Total mundo & 2.455 .250 & 2.728 .480 & 2.754 .373 \\
\hline
\end{tabular}

Fonte: Recueil de données mondiales sur l'éducation. Institut de Statistique/UNESCO, 2006, 2007 e 2008. 


\section{muralpesquisa}

2.754.373 (UNESCO, 2008). Quais seriam os países campeões em emissão de estudantes? Onde estão localizados? O que têm em comum?

Considerando apenas aqueles que enviaram mais de 50.000 estudantes, em 2006 (UNESCO, 2008), coincidentemente, todos estão situados no continente asiático e se integram à economia mundial como países semiperiféricos: China (417.351), Índia (139.459) e República da Coreia (101.913). Esses países têm em comum acelerado processo de crescimento econômico, nem sempre acompanhado pela consolidação quantitativa e qualitativa do sistema de educação superior nacional. Assim, a dependência da expertise alcançada pelos países desenvolvidos é fundamental para todos eles.

Determinados a ultrapassar essa limitação de forma mais rápida, governos e famílias investem sobremaneira na formação internacional dos jovens universitários em áreas que consideram estratégicas para a manutenção da taxa de crescimento da eco- nomia do país e para a promoção individual. Não é de se estranhar que aproximadamente um quinto dos estudantes internacionais sejam chineses, indianos e coreanos (Tabela 2).

Qual seria o destino preferido pelos estudantes internacionais? Enquanto a preferência dos asiáticos recai sobre as instituições estadunidenses, o Reino Unido é o país preferido pelos europeus. As instituições européias (Alemanha, França e Espanha), por sua vez, são preferidas pelos estudantes do Norte da África (Argélia, Marrocos e Tunísia, particularmente).

Em quais termos explicar tais rotas? A crescente valorização do conhecimento, combinada ao encolhimento dos investimentos públicos em educação superior, tem levado as universidades públicas dos países hegemônicos a diversificarem suas fontes de recursos financeiros, com a comercialização de serviços educacionais, e a promoverem ambiente propício à privatização do setor além da respectiva desregula-

Tabela 3 - Recepção de estudantes internacionais nos países da América Latina e Caribe (2001-2006)

\begin{tabular}{|c|c|c|c|c|c|c|}
\hline Países & 2003 & 2004 & 2005 & 2006 & 2007 & 2008 \\
\hline Argentina & 3.255 & 3.343 & 3.261 & 3.261 & - & - \\
\hline Bolívia & - & - & 1.142 & 1.142 & - & - \\
\hline Brasil & - & - & - & 1.260 & 1.246 & 1.117 \\
\hline Chile & 3.477 & 4.883 & 5.211 & 5.211 & 1.966 & 1.966 \\
\hline Costa Rica & - & - & - & 1.560 & 1.560 & 1.374 \\
\hline Cuba & - & - & - & 13.705 & 14.414 & 26.889 \\
\hline México & - & - & - & 1.892 & - & - \\
\hline Uruguai & 2.100 & 2.100 & 2.100 & 2.100 & - & - \\
\hline Venezuela & - & - & - & 2.472 & 2.472 & 2.472 \\
\hline
\end{tabular}

Fonte: Recueil de Données Mondiales sur l'Éducation. Institut de Statistique/UNESCO, 2003, 2004, 2005, 2006, 2007 e 2008. 
mentação. Prova disso é que o deslocamento de estudantes internacionais é mais expressivo entre os países que instalaram um sistema de educação superior predominantemente privado.

Entre os países europeus a mobilidade acadêmica é estimulada como forma de integração cultural, social, política e econômica. Com a formação da União Européia, vários programas de incentivo à formação superior, aprendizagem de línguas, capacitação profissional etc. têm sido implantados. Por exemplo, Eramus, Comenius, Lingua, Leonardo da Vinci e Tempus.

Já na América Latina, apesar de os países estarem em sintonia com a média mundial de investimentos em Educação (4,4\% do PIB) (UNESCO, 2007); da maioria ter investido na formação de universidades ainda no período colonial; da região abrigar nove universidades bem pontuadas na classificação das 500 melhores instituições de educação superior do mundo (Academic Ranking of World Universities, 2007) e das barreiras culturais e linguísticas serem modestas quando comparadas com os países da União Européia, a sua capacidade de atração de estudantes internacionais é a mais baixa no globo. É a única região que entre 2004 e 2005 apresentou redução no efetivo de estudantes internacionais, de 36.536 para 33.987 (UNESCO, 2006; 2007).

A maioria esmagadora dos estudantes é oriunda dos países da América Latina e Caribe. Cuba acolhe 11.867, Venezuela atrai 2.060, Chile 1.088 e Costa Rica 1.015 recebem pouco mais de mil estudantes, respectivamente. Possivelmente, o fato de Cuba ter investido em um sistema de educação pública e se destacado nas áreas de Educação e
Saúde Pública influíram na captação de estudantes provenientes de todos os continentes.

O desequilíbrio encontrado entre os números que expressam a internacionalização ativa $e$ passiva na grande maioria dos países da América Latina é significativo. Enquanto a recepção de estudantes está restrita a cinco países, segundo relatório de 2007, o envio de estudantes atinge praticamente todos eles. O Brasil acolhe 1.246 estudantes, envia 20.778; o Chile acolhe 1.966 estudantes, envia 8.679; a Venezuela acolhe 2.472 , envia 10.694. Contudo, observa-se relativo equilíbrio na Costa Rica (acolhe 1.560, envia 1.716) e desequilíbrio positivo no caso de Cuba (acolhe 14.414 e exporta 1.688). O destino preferido são os EUA. Dos 116.904 estudantes originários do México, Brasil, Colômbia, Peru, Venezuela, Argentina, Chile, Bolívia, Uruguai, Costa Rica e Cuba, 48.678 foram para lá em 2005 (UNESCO, 2007). Entre países de língua espanhola, a Espanha aparece como o segundo destino preferido, com 16.001 estudantes.

Apesar de o Brasil ser responsável por 2\% do PIB mundial e 57\% do PIB da América do Sul, a sua participação no sistema de educação mundial é modesta e até o momento dependente do financiamento público porque permanece voltada para a formação de quadros capazes de fortalecer a pós-graduação stricto sensu. Contudo, o atual governo investe em projetos que promovem a internacionalização ativa com a criação três universidades públicas federais, de natureza supranacional, comprometidas com a promoção da inclusão social e da integração regional por meio do conhecimento e da cooperação solidária: UNILA, UNILAB e a UNIAM.

MANOLITA CORREIA LIMA, Professora da ESPM, mclima@espm.br 